\title{
Foreign language virtual teaching optimization: sensory-somatic enhancers as an alternative to rational and emotional ones
}

\author{
Nataliia Slukhai ${ }^{1}$, Liudmyla Slavova ${ }^{1, *}$, Sergii Slukhai ${ }^{2}$, and Maryna Omelianchuk ${ }^{3}$ \\ ${ }^{1}$ Institute of Philology, Taras Shevchenko National University of Kyiv, 14 Shevchenko Blvd., Kyiv, 01601, Ukraine \\ ${ }^{2}$ Faculty of Economics, Taras Shevchenko National University of Kyiv, 90a Vasylkivska Str., Kyiv, 03022, Ukraine \\ ${ }^{3}$ Potebnia Institute of Linguistics of the National Academy of Sciences of Ukraine, 4 Hrushevsky Str., Kyiv, 01001, Ukraine
}

\begin{abstract}
Based on the use of potentials of human analogue thinking and cognitive effects as an indispensable component of the cognitive activity, the article considers atypically located in the frame structure and suggestively loaded rational and emotional motivators for learning a foreign language. The article focuses on sensorysomatic enhancers of the new information reception. It is shown that stimulation of the analogue language learning is mostly successfully carried out with suggestive or emotional motivation, as well as through visual, audio, kinesthetic channels alongside with the verbal one during games. It is proved that such games were used in the history of human ontogenesis. Game resources of virtual reality are considered as new stimulating suggestions, since a game is a way to detach from the profane in favor of the sacred information space. The ways of optimization of virtual foreign language learning by means of sensory-somatic enhancers are described.
\end{abstract}

\section{Introduction}

Observing the foreign languages learning process in the context of globalization, intensification of the information flow and the improvement of digital reality shows that the triad "teacher - the language being studied - student" is rapidly being modified into the dyad "the subject mastering the language - the language being studied." The role of the mentor in relation to the personality is steadily decreasing in all spheres of human activity, including the sphere of acquiring new knowledge. Since language retains its status of the main intermediary between a human and the world, only the personal resource of the subject mastering the language can be emphasized in the processes of language learning intensification - moreover, the virtual learning channel is steadily turning into a dominant one. The process of acquiring new knowledge, including the study of foreign languages, is an objectively timeconsuming process. Using the personal resource of the subject, organizers of the educational process are required to turn the learning process into a funny and effective one using optimal tools. This task prevails in terms of new challenges that humanity faces, like the current situation of COVID pandemic. This determines the relevance of the study.

Self-study has always been regarded as an important way of learning a foreign language. A major aim of education is to prepare students to continue self-directed learning throughout their lifetimes. In our rapidly changing world there has appeared a need for a paradigm shift in the perception of learning. In this connection a wide range

\footnotetext{
*slavovall16@gmail.com
}

of educational concepts has been developed with the focus on self-study: self-directed learning, self-determined learning, self-regulated learning.

A person is regarded as an active system capable of self-regulation and self-organization [1]. The concept of "self" is an important motivational value. Self-regulation constructs nicely integrate the cognitive, motivational, social, and behavioral strands of theory and research [2]. People are not conscious of the cues that control a great deal of their behavior [3]. Learners' self-direction is defined as the ability for self-directed and self-regulated independent learning processes [4].

The self-studying (autodidactism) paradigm seeks to find out the ways of influencing a person that bring the "system" to a new favourable path of development; it is self-managed and self-sustaining. In its broadest meaning, self-directed learning describes a process, in which individuals take the initiative, with or without the assistance of others, in diagnosing their learning needs, formulating learning goals, identifying human and material resources for learning, choosing and implementing appropriate learning strategies, and evaluating learning outcomes [5]. Among the benefits of students' self-study are the following ones: improved academic performance; increased motivation and confidence; greater students' awareness of their limitations and ability to manage them; enabling teachers to provide differentiated tasks for students.

In the era of the dominant digital learning, the role of self-study in the process of learning foreign languages is steadily increasing; this requires a search for original forms of optimizing the process of acquiring knowledge, increasing its effectiveness, and activating the learners' personal resources. 
As a natural effective enhancer of learning a foreign language, we have studied analogue human thinking and the resource of cognitive distortions. The proper use of both significantly reduces the time spent on mastering a new language. The following previously obtained conclusions appear to be fundamental in optimizing language learning. Firstly, knowledge of one of the languages of the language group (English in the Germanic group, Latin in the Romance group, Ukrainian or Russian in the Eastern Slavic group) significantly reduces the time of learning the languages of the same group using the principle of analogy - of high, medium, low associativity or full analogy (represented by international vocabulary). Secondly, very good results are achieved by the implementation of the dissociative principle in the formation of special interest in dissociates in terms of the increased focus on attractive objects (mastering lexemes denoting cultural unique things, or, on the contrary, ethno-specific forms denoting cultural universals). Thirdly, the principle of analogy in language teaching in the fields of associates and dissociates is highly effective taking into account the resources of cognitive effects, i.e. the characteristics of deviations of human thinking from cognitive impeccability in getting to know the world, and in this case, cognitive effects are considered as a reserve for accelerated language learning. Fourthly, cognitive illusions, in particular, the illusion of quick mastering a language, facilitate the frame-discursive use of the language in pragmatically significant situations, with inevitable errors, but maintaining high communicative relevance. The main conclusions regarding the possibilities of analogue learning are presented in a number of studies [6, 7]. Analogue learning forms the platform of immersive learning, since it involves obtaining real experience in a real environment, blurs the line between theory and practice, brings language learning and solving everyday problems as close as possible. Analogue teaching through virtual channels is quite promising as an immersive learning platform.

Awareness of the prospects of analogue (associative and dissociative) teaching and frame-discursive use of the language raises the question of stimulating the learner to speed up language learning through rational, emotional and especially sensory-somatic immersive technologies (immersion technologies with an evident effect of sensory perception), primarily augmented reality technologies [8], highly-demanded today in the advanced areas of communication, namely telecommunications, political, advertising, medical, in the art sphere, and even the religious one. All of them are directed to the sub-consciousness, they are suggestive in nature and require effective modification of motivators.

The sensory-somatic approach is relevant as a learning tool in general, but it is especially promising for learning foreign languages, not because the language contains a significant number of lexemes, the meaning of which contains the somatic component, but because a language, the most important human marker, is mastered by sensory channels, which can and should perform the common function of channeling information, enhanced by the capabilities of the computer, in digital learning conditions.
One of the advantages of immersive technologies significant cost savings for learning at the expense of replacing the teacher in the process of learning by 3D object should be complemented by an increase in the effectiveness of teaching, i.e. the effect of mastering the material should not be the result of not so much the use of technology as the use of simple augmented reality technologies in progressive methods of teaching a language.

The aim of this study is to identify ways of effective modification of motivators for learning foreign languages - traditional (rational, emotional) and new - technologies of augmented reality in learning foreign languages using the resources of sensory-somatic enhancers, similar to the games of the New Code of Neuro-Linguistic Programming (further referred to as NCNLP games). To achieve this goal, we set the following objectives:

a) to summarize the research efforts on traditional (rational, emotional) motivators for learning foreign languages and, through a survey, determined the place of sensory-somatic enhancers among others for learning,

b) to determine the role of sensory-somatic enhancers in traditional methods of teaching foreign languages,

c) to identify the perspective of using sensory-somatic enhancers in modern virtual learning technologies by analogy with the NCNLP games, found their cognitive prototype in children's games,

d) to determine the possibility of quick identification of student belonging to the group of dominant sensory perception on the basis of the results of students' questionnaires,

e) to find out the main directions, ideas following which it is possible to provide a synergistic effect of analogue teaching and augmented reality methods, including sensory-somatic enhancers.

\section{The state of the problem: the role of virtual technologies in teaching a foreign language}

With the advent of the digital space and virtualization of teaching, the process of mastering a foreign language has undergone significant qualitative changes due to the emergence of new immersive technologies. With the view of technological advances, the educational process is required to meet the demands regarding new forms and tools of training students, integration of an individual into the national and world culture. Students, in their turn, develop and demonstrate their level of professional and IT knowledge as well as skills adequate to the modern level of science development.

Due to the digital age and appearance of new virtual technologies the processes of teaching and learning foreign languages have undergone drastic changes. Everyone is now mastering new ways of processing information as the main resource of development. This process has not only technological but also social significance. We 
are experiencing a historic period of rapid technological changes, the emergence of new information technologies, virtual communication, computer/mobile equipment, and mastering modern IT tools. This process influences all spheres of life, including education. Analogue teaching practices are more and more often replaced by digital ones. This fact causes the change regarding the role of a teacher, its shifts from providing the content, giving ready-made knowledge to content facilitation and researching using the Internet and special software.

Nowadays, on the one hand, technology offers the flexibility to use a combination of tools and methods to help students absorb new information and, on the other hand, IT offers many powerful tools for teachers. The benefits of using IT in language learning/teaching are obvious; it is interactive, meaningful, and measurable. Multimedia content is widely applied in virtual reality tools. According to Bent B. Andresen and Katja van den Brink, videos, images, sounds, animations and simulations can be effectively used in a meaningful way due to their interactivity and flexibility [7].

Among virtual technologies that have gained on popularity m-learning [9-11] and cloud computing technology $[10,12,13]$, digital video games $[14,15]$ can be mentioned. Virtual technologies are particularly relevant to language learning/teaching due to the fact that they present language learners with situations similar to those found in the real world $[16,17]$.

The development of systems analytics and digital technologies made it possible to search for learning enhancers outside the common space of the mind or consciousness: "Natural selection creates complex functional machinery without mindfulness; evolution lies inside the space of optimization processes but outside the circle of minds" [18].

Among new forms of transmitting educational information in the framework of the global information computer network, we have analyzed specialized sites, video training, mobile applications, single and multi-user video games, social networks aimed at communication of native speakers of the languages studied [19-22]. All of them are capable of stimulating the learning of a foreign language to a different extent, but their stimulating potential, in our opinion, is significantly inferior (due to ontogenetic formation) to the effectiveness of sensory-somatic enhancers, which are promising for analogue teaching of a foreign language. The use of suggestive techniques in the learning process also plays a significant role.

It should be recognized that it was long ago when scholars and teaching practitioners dealt with teaching foreign languages through the use of sensory-somatic enhancers. Even a group of extensive methods of teaching foreign languages, based on the acceleration of learning due to a quantitative increase in time, technical teaching aids, study material, etc., included methods based on two sensory systems - such as audio-lingual and audio-visual methods.

The audio-lingual method involves multiple listening and subsequent pronunciation of speech patterns of any length up to the automation of speech structures reproduction; the method is based on the use of records on infor- mation carriers of any type and assumes relying on the auditory canal of perception. The audio-visual method involves mastering the language through oral dialogical speech, reproduction of the sound pattern as a single sample (sound, intonation, stress, rhythm), but dialogic speech is presented not in a situation of direct communication, but by means of off-screen accompaniment of filmstrips. The method presupposes relying simultaneously on the auditory and visual channels of perception; it is based on imitation, memorization and reproduction by analogy. The offscreen accompaniment of filmstrips can be considered as an early and simple form of using the possibilities of augmented reality when teaching foreign languages. These forms were even more widely used in teaching using intensive, or suggestive, methods based on the principle of accelerating learning per unit time by appealing to the reserve capabilities of the human psyche.

Suggestive methods in the broadest sense include two sensory-oriented ones. This is the method of gnoseodrama, drama-pedagogy, the essence of which is the implementation of the learning process in the conditions, firstly, of the unity of verbal and non-verbal communication components, and secondly, active actions of students, situational role mimicry and improvisation, thirdly, high emotional intensity, fourthly, exaggerated clear articulation of the text, which generally resembles the performance of a drama on the stage. One more method is situational, or Hi-Tech, method that presupposes training using the Internet communication based on visual, audible paradoxical situations (based on aphorisms, jokes, etc.) in the course of interactive communication that promotes learning lexical and semantic connections of words. Augmented reality technologies (like a colorful image of sacred situations - fairy tales - or profane - a meeting of two friends) when used with the Hi-Tech method are enriched by immersive technology resources (e.g., the movement of a student or movement of his/her arms and legs is imitated).

Suggestive methods in the narrow sense include several ones. It is a method of suggestopedia, going back to the teachings of G. Lozanov (Bulgaria). "The basis of suggestive training, according to Lozanov, is based on three basic principles: 1) the principle of joy, absence of tension and concentrated psychorelaxation, 2) the principle of unity of the conscious - paraconscious and integral brain activation; 3 ) the principle of suggestive relationship at the level of the reserve complex" [23]. The activation of the reserve abilities of the psyche takes place under the conditions of using favorable learning conditions, in particular, the musical background (especially Baroque music), which is considered as attracting extraneous audio signals for accelerated language learning.

The suggestive cybernetic teaching method should also be mentioned. It was developed in the 1970-80s by V. Petrusinsky (Russia). This is a method of immersion in the language environment when you need to master the language quickly. The average development period is 8 days, 15 hours a day (to learn the language from scratch; two such courses were conducted with an interval of 2-3 months). The stimulus material was introduced in a large 
quantity, very quickly, using strobe lights and movie cameras, and was repeated several times. The video was accompanied by the texts of psychotherapists providing relaxation for a student. The method is called "suggestive cybernetic" because the training was carried out using cybernetic means that activated the unconscious components of mnemonic activity - a system of special techniques that serve to facilitate memorisation. This method went down in history as one of the effective methods of teaching foreign languages precisely thanks to the aggressive and massive use of augmented reality technologies.

Among the intensive methods of suggestopedia in the narrow sense, the rhythmopedic method developed in the 1980s by G. Burdeniuk (Moldova) should also be mentioned as a method of using sound effects external to the subject, which are nevertheless effective for teaching. The method is based on the sensory rhythm stimulation of a student who is in a state of hypnotic sleep. Rhythm stimulation is the action on the human psyche of low-frequency impulses of color, sound, touch, which are perceived by analysers of the corresponding type - visual, auditory, kinesthetic. The material introduced in this way is remembered three times faster and stored two to three times longer than the same one when using other methods.

We have studied the suggestive potential of impetus for learning foreign languages. Impetuses are verbal (rarely nonverbal) enhancers for actions aimed at motivating a person and forming the desire for creative behavior. Impetuses have always played a significant role in learning foreign languages, however, with the development of the Internet, this role has increased, and the nature of enhancers has changed. The specifics of modern virtual impetuses preconditioned by the use of suggestive techniques, has two features.

Firstly, as a part of the impetus, the suggerend anchoring phase is prolonged and the trance induction/utilization phase is reduced or the last two are aligned with the anchoring phase, as in the text given below, where anchoring is combined with trance induction and partial utilization, and only the last echo phrase represents utilization "in its pure form": "In our life we set goals many times, achieve them and set new ones. The ability to overcome obstacles begins with small victories over oneself and one's laziness. Foreign language lessons, like nothing else, show us what form we are in. Being engaged in the learning process only 15-20 minutes every day, you are guaranteed to succeed in learning and experiencing what it is like to be a winner. Do not miss your chance" (https://www.hosgeldi.com). This requires reconstructing the anchoring map as the main component of the motivator text frame. A rational map of anchoring is based on ratiogens, including promises, goal substitutions, implanted motivators and anticipations; the emotional anchoring map is based on emotions, including stroking, slogans and chants, truisms, intrigues, attractions, analogue texts, appeals to authority, majority opinion or precedent texts, and sensorogens. The emotional and rational maps are balanced: the emotional map contains a smaller number, but higher variety of anchors, the rational map contains a quantitatively bigger number of anchors which are represented in a smaller variety, i.e., the emotional map "underruns" the rational one. Let us pay attention to the significant role of the emotional component as a part of motivators and the presence of sensorogens as a part of the emotional map (as "new knowledge early in the morning invigorates better than the contrasting shower!"; "Our memory is subject to training even better than our muscles").

Secondly, the classical structure of the motivational communication frame ("Let the students preparing for the seminar today read a new article on the history of cognitology in the library hall") has been preserved. However, its interpretation in motivating texts has undergone significant changes in the direction of strengthening the positions of time and purpose. They are dependent on actions/states, and reductions of the subject and object positions, and not fixed positions of attributes and space. For example, "today you have 1440 minutes. Use them wisely. Spend at least five minutes on self-study." An analysis of the texts of online motivators for learning foreign languages in terms of built-in means of suggestive influence showed their significant number and variety, as well as a two-channel (rational and emotional) influence even in modern unsophisticated pragmatically oriented works of a petty form, due to the influence of a stable pedagogical tradition.

Thus, it is fair to say that historically the use of suggestive motivational and teaching methods, the sensor and somatic code has occupied a worthy place among teaching methods in the framework of extensive and, especially, intensive methods of teaching foreign languages. However, there are spheres where sensory-somatic regulators in the process of training have demonstrated their extremely high potential.

\section{NCNLP games as a tool for enhancing human cognitive activity}

Sensory-somatic stimulation is an educational modification of the NCNLP game, which is based on ontogenetically determined resources of the human central nervous system and body, in particular, on the conclusions as for the three-layer structure of the human brain, which incorporates the reactions of the reptile brain, which controls respiration and pulse; mammalian brain, which controls the limbic system, basic functions and emotions, and the human brain [24].

The doctrine of the existence of four types of people's "imagination": visual, audible, motor, or kinaesthetic (according to modern ideas, the last group includes gustatory and olfactory as the dominant sensory modality), as well as the fourth one, verbal (audio-digital), is known to have been introduced in the 19th and early 20th centuries by W. James [25], and since then this doctrine has acquired features of completeness.

The NCNLP games were proposed by G. Bateson, an Anglo-American anthropologist and system analyst who combined communication theory with modern advances in cybernetics. One of the ingenious ideas embodied by Bateson was to find correlations in the game between sensory and mental reactions: "All of these considerations 
work together to set the mind in special relation to the body. My arms and legs obey one set of laws and equations in terms of their purely physical characteristics - weight, length, temperature, etc. But, chiefly owing to transformations of quantity... my arms and legs obey quite different laws in their controlled motions within the communication systems I call "mind" [26]. According to Bateson, the game is a conventional name: "... play is a phenomenon in which the actions of "play" are related to, or denote, other actions of "not play." ... the evolution of play may have been an important step in the evolution of communication" [27]. As sensory modality is a genetically long-established human response to a stimulus, including speech stimulus, Bateson's NCNLP games, created in the second half of the 20th century, combined speech stimulus and visual (Rainbow game), tactile (Alphabet game, Square Breathing game), auditory (Alphabet game) ones, potentially - all three, which cause sensory support and speech stimuli reinforcement, simultaneously the harmonization of the interaction of the hemispheres and suggestively conditioned unloading of the subconsciousness. Today there are dozens of such games.

Games are one of the most important sources of NCNLP - a system of creative self-improvement, selfmanagement, personal development, the ability to manage one's own states, ensuring harmonious interaction between conscious and unconscious, making quick intuitive decisions. The purpose of the NCNLP game is to achieve a "highly productive resource state". This is an outwardly oriented dynamic trance state, similar to creativity, a state of "pulling in the flow", abandonment of intense exclusively conscious search for a solution, a state of waiting for spontaneous exit from the subconscious during conscious meditation, when the right and left hemispheres (systemically distributed and holistic, detailed and holistic, analytical and creative, figurative) of the brain are harmonized to a greater extent than usual, a balance is established in the treatment of the situation by the conscious and unconscious. A highly productive state is achieved in order to activate all the resources of the human brain, all human sensory systems, especially representative ones (visual, auditory, kinesthetic); activation of both hemispheres of the brain for parallel processing, adjustment (scaling) of the existential code to the creative one [28].

It should be noted that today the flow theory of the M. Csíkszentmihályi, known for his research on the phenomena of creativity and subjective happiness, "flow states", which provide satisfaction from all activities, has gained considerable interest. The state of flow is the opposite of entropy (nothingness, chaos, "sleep of the mind that generates monsters", according to F. Goya), the optimal state of harmonization of mental and physical "I" of a person, which provides job satisfaction and high results, a state of positive experiences created by controlled emotions, feelings, impressions, a state of complete situational involvement in activities that bring maximum satisfaction, "Happiness, in fact, is a condition that must be prepared for, cultivated and defended privately by each person" [29], it begins with "control over consciousness". "In flow we are in control of our psychic energy, and everything we do adds order to consciousness". Thus, a person in a flow state is capable of rapid creative mastering of new knowledge, including mastering of new languages, and the researcher's task is to find effective mechanisms for introducing a modern recipient into the flow state (see [30]). It may seem surprising, but analogues of children games can act as a sensory channel for introducing a learner to the flow state.

\section{Traditional children's games with the use of sensory-somatic stimulation as an ontogenetically formed tool for enhancing human cognitive activity}

It is believed that the genius of Bateson allowed combining verbal and sensory codes to ensure a highly productive resource state of the brain. Bateson's contribution is undeniable and rather significant. However, we drew attention to the fact that such games in large quantities contain children game communication. Games based on sensory-somatic enhancers are among the most interesting and complex ones; they are inherited from generation to generation.

This statement is true for children games, where audio reproduction of a verbal text involves tactile stimulation. In the East Slavic region, there is Horned Goat Is Coming game ("Ide koza rohataia") where a playful and threatening voice is accompanied by the rotation of two fingers spread like horns, or Grey Bunny Is Sitting game-saying ("Sydyt zaichyk sirenkyi").

This is especially true for the most popular children games for seniors and teenagers. In the East Slavic region, it is a game of verbal-audio identification, Chinese Whispers game, which involves the perception of an audio verbal signal and its transformation based on losses in the communication channel during the transmission of many participants in the chain. Losses are predictable and often intentionally stimulated, i.e. losses in the audio channel stimulate the appearance of a new verbal signal for the sake of which the game is played.

Verbal-visual identification games are based on a combination of verbal and figurative visual codes. Guess What It Is game can serve as an example, when one thinks of the subject, and the other has to guess which one, based on the questions, the answers to which are only "yes" and "no": "Is it a living being?" - "Yes, it is." "Is this a plant?" "No, it isn't." "Is this an animal?" - "Yes, it is." "Is this a mammal?" - "Yes, it is." "Does it have 2 paws?" - "No, it doesn't." "Does it live on land?" - "No, it doesn't." "Is this a dolphin?" - "Yes, it is!"

Verbal-kinesthetic identification games are based on a combination of verbal and kinesthetic codes. My Wooden Cap game is based on the repetition of the quatrain: Ukr. "Kovpak mii derevianyi, / Derevianyi mii kovpak. / A yakshcho ne derevianyi, / To tse ne mii kovpak!". Then the presenter asks not to say the word "mii" (my), but to replace it with a gesture (point to yourself). Then the word "kovpak" (cap) is replaced by a gesture: touching the forehead, the word "ne" (not) - by shaking your head, the word 
"derevianyi" (wooden) - trampling of the feet. There are a lot of similar rhythmic kinesthetic games.

In East Slavic game culture, more complex phenomena are observed, such as the game of complex verbal-visualkinesthetic identification, Three-Liter Jar game (one of the participants says aloud the first letter of the alphabet "a", and then silently continues to count: Ukr. "b", "v", "g". The other participant must say at any time, "Stop"). Everyone will name words starting with the letter where the player has stopped. Moreover, they can give only those words that can be placed in a three-liter jar.

Undoubtedly, similar games exist in other cultures of the peoples of the world (e.g., My Wooden Cap game is equivalent to the English one "My hat, it has three corners", Swedish "Min hatt, den har tre kanter", German "Mein Hut, der hat drei Ecken", Spanish "Mi gorro tiene tres puntas", French "Mon chapau a quatre bosses", Hebrew "La Kova Shelie Shalosh Pinot", etc.).

Similar games are used by adults - to ensure stress resistance, for example, in the military sphere French Relay Race game [31], to train memory by learning mnemonics and skim reading (the task is to read the text quickly while clapping the hands, touching the tip of the nose with the right or left hand in turn, simultaneously drawing a square on the floor by one foot, silently counting from 10 to 0 , while perceiving a loud story of the lecturer on the theory of the question).

As we can see, kinesthetic signals dominate among the sensory-somatic ones. This result correlates with the established opinion that kinesthetic impressions were ontogenetically dominant, and not visual and auditory ones, which today are often included in the list of the most important sensory-somatic reactions. Although in the times of ongoing digitalisation we observe the intensification of the process of recoding the information perceivers into visual learners.

\section{Methodology of teaching foreign languages using sensory-somatic enhancers}

Introduction of a person to the state of flow should be an important task in learning a foreign language. Experience shows that an important tool for achieving this is, in particular, language acquisition due to the use of sensory support, which is possible by relying on ontogenetically formed traditions of children games described above and analogues of the NCNLP games.

To assess the significance of sensory-somatic enhancers, we conducted two surveys.

Respondents of the first survey were philologists, bachelor students majoring in Russian Language and Literature, Foreign Language (30 students) and Translation (30), graduate students of the second year (12) and users of two messengers - Viber, WhatsApp (30). Respondents were given a questionnaire consisting of several questions.

As for the first question "What form of learning a foreign language would you choose as more promising - a real or virtual format", the answers of philologists were

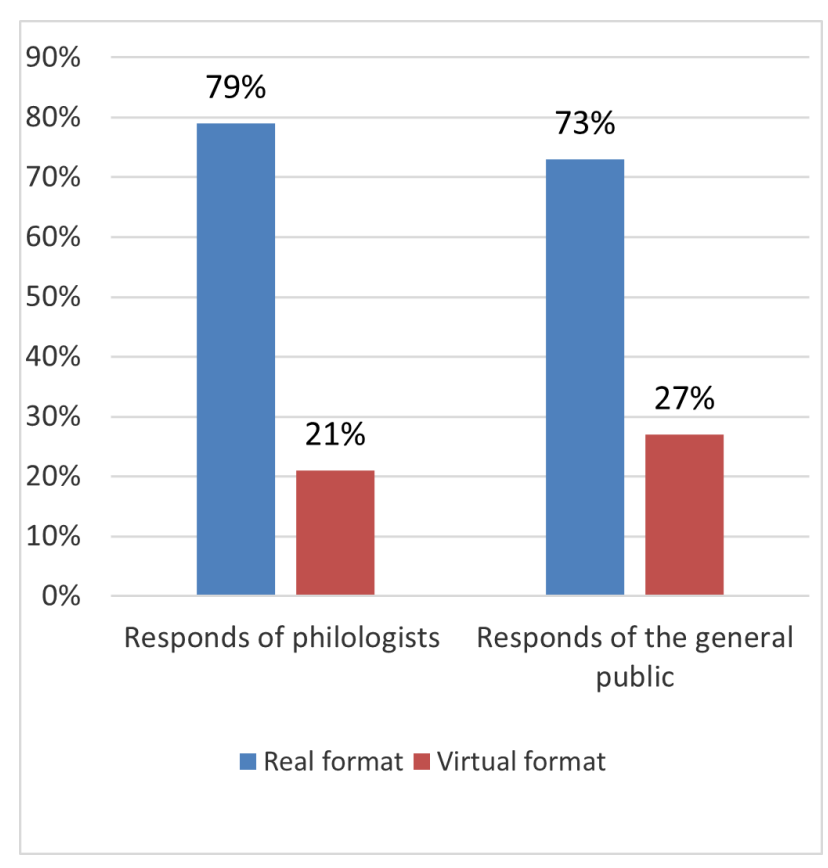

Figure 1. Preferences concerning learning language format

distributed in the ratio of 79\% (real format) and 21\% (virtual), answers of general respondents - 73\% and 27\% respectively (figure 1). Mankind is obviously moving towards the assimilation of information mainly through virtual channels, but the answers have shown that the prospects of learning through virtual channels are not yet realized by either philologists or the general public.

As for the second question "What motivators do you think are more effective in stimulating the study of foreign languages - sensory-somatic, rational or emotional" (2 examples were given), the answers of philologists were distributed as $11 \%, 51 \%$, and $38 \%$, and those of the general public - respectively 13\%, 60\%, and 27\% (figure 2).

It follows from the answers that sensory-somatic enhancers (as well as emotional) are perceived as less effective than rational, which traditional pedagogy is based on, that means that rational enhancers are fixed by consciousness, emotional and especially sensory are less noticeable, i.e. potentially more effective in learning.

The respondents of the second survey, conducted in Taras Shevchenko National University of Kyiv in 20192020, were PhD philology students of the second year of study (34 people), and MA students of the second year of study (8 people) who took a course in Linguistic Programming of Human Behavior. Its programme presupposed learning three leading NCNLP games (Alphabet, Rainbow, and Square Breathing). Conducting this study, we set two goals: firstly, to assess the effectiveness of games based on sensory somatic stimulation aimed at decluttering the mind overloaded with mental activity and harmonize the activities of the hemispheres of the brain; secondly, to search for analogues of these games among the children games of the respondents.

Typical comments from $\mathrm{PhD}$ students included the following. Alphabet game (a game of simultaneous naming 


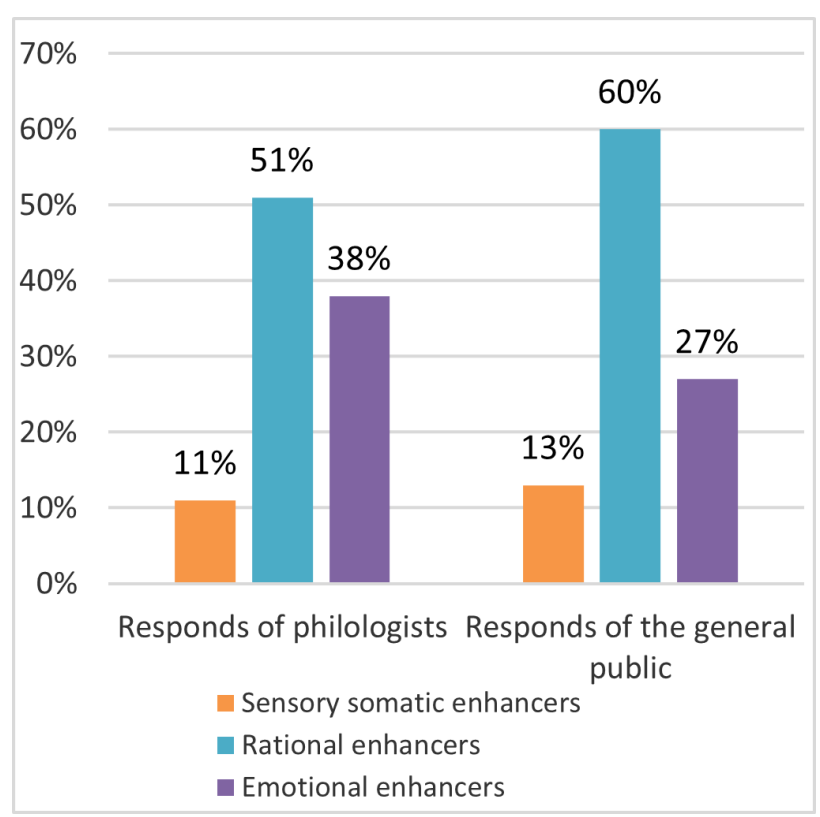

Figure 2. Preferences concerning stimulation

the letters and synchronous raising of the right, left hand, or both hands at 90 degrees angle) is interesting, exciting, stimulating; it activates visual and spatial perception, synchronizes the hemispheres well: it is easy to perform both analytical and creative tasks after the game (10 answers). Rainbow game (in terms of dissonance of the color scheme of the background, the verbal name of the color and the color of the name itself it is necessary to name the color on the basis of the name of the real color of the object) is a great game that helps not only distract and "unload" the mind, but also train attention and, therefore, harmonize both hemispheres, it causes a feeling of the "brain" rest from all thoughts, a feeling of emptiness, the impression of a seemingly bifurcated consciousness, a pause from reloading work that requires constant concentration and nervous tension; a gambling game that qualitatively distracts from any other thoughts, after playing it there appears a feeling of "empty thinking", as if there were no thoughts in the head (11 answers). Square Breathing (breathing for 7-8 minutes according to the scheme inhale - pause - exhale - pause counting to five in each phase) is a very interesting exercise that aims to calm and concentrate the personality on the inner state; enter a state of complete relaxation with absolutely detached thoughts, when thoughts are focused only on breathing and numbers; is the most pleasant, similar to breathing exercises in yoga, very similar to meditation, a good method of overcoming anxiety, rather designed to improve blood supply and increase oxygen levels in the brain, which will quickly enable to achieve a highly productive state; after a few minutes of that exercise, you feel relaxed and restored, as if returning from somewhere to this world; the feeling that you have managed to completely distract yourself from everyday thoughts and worries; the feeling after this game is similar to the feeling after Rainbow game; it brings a feeling of calm, rest, "empty head" (11 answers). PhD

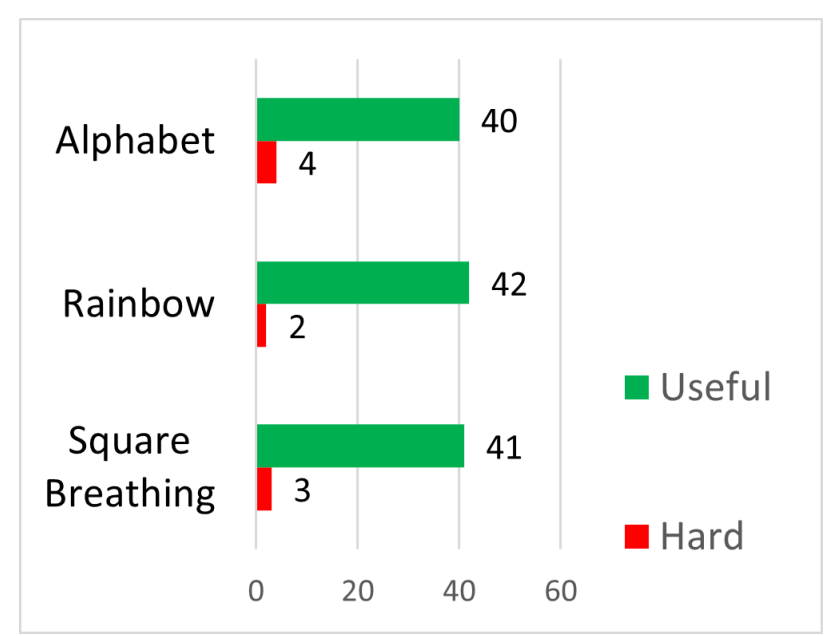

Figure 3. Audience reactions to the NCNLP games

students easily found in memory similar children's games confirming the G. Bateson's opinion that conscious perception has the properties of the image [32]. The reactions to the games are presented in figure 3 .

When asked to find analogues for games in childhood, we received positive responses with extensive comments and examples from 42 respondents out of 44 (95.5\%).

Thus, the NCPLP games perform the role of decluttering the tired mind and harmonizing the right and left hemispheres of the human brain. Many years of experience of using these games in the classroom and reflections have led us to realise that they are a complete analogue of historically formed, established and systematically used games for children, and therefore, can serve the purpose of productive learning and simultaneous unloading of consciousness, including foreign language learning. Such experience exists. The expansion of virtual technologies in the learning process was considered in detail in the works by some authors [33], the use of immersive technologies [34]; the transition to multimodality in teaching was considered by A. Zamkov [35]; method of multimodal interaction using games was considered by Lv et al. [36]. In Russia and Ukraine, augmented reality technologies were extensively studied as a means of learning a foreign language [22, 37-39]. We consider the last of the directions to be extremely promising.

In Ukraine, when teaching foreigners the Ukrainian language, productive and interactive tasks similar to the Rainbow game are used, such as: printing students cards with the names of colors that name each color on colored paper of another color and the task is to name the color in which the word naming the color is written. Likewise, tasks similar to the Alphabet game are used: auditory recognition of words belonging to a certain thematic group, based on chaotic naming of words, presupposes raising the right hand, only in case if that word belongs to the chosen topic, and raising the left hand if it is referred to any other thematic group. But these simple techniques will acquire a different quality if you use immersive technologies that are actively advancing in the educational pro- 
cess, but rarely take into account the resources of sensorysomatic reactions of a person.

Augmented Reality is the simplest, most effective (due to active sensory-somatic involvement in the learning process) and ergonomic (reducing time and improving results) kind of immersive technology. It complements "Real" Reality with virtual codes - from verbal to static or dynamic (animation) virtual images, which cause mental, sensorysomatic reaction of the student at the same time, similar to the reactions of NCNLP games and their analogues. The essence of augmented reality is to introduce to the network of cognitive perception of the student the results of sensory processing of the world to improve the perception of information. Three stages of training on the basis of Augmented Reality technology are offered: preparatory, non-situational training and the stage of frame situational training.

Teaching a foreign language using the sensory-somatic code and principle of analogy involves at the preparatory stage the division of group students into three subgroups on the basis of self-identification regarding belonging to the carriers of visual, auditory, kinesthetic "predicates", understood by the NLP representatives as verbal objectification of a particular information system, or a representative system based on sensory data.

The possibility of such self-identification was controlled in the group of 16 students of the 3rd year of study. Students were offered lists of potentially used "sensory predicates" in public speaking, divided into three parts of speech. Students were requested to determine their type of the representative system, indicate the level of identification difficulty (from one to three) and the time spent on identification. Predicate lists were compiled on the basis of a selection from the dictionary [40], shortened and presented in equal numbers (about 300 objectifications in each block). E.g. the following ones:

- A visual predicate block. Nouns: stage, shine, vision, visibility, business card, appearance, flash, signboard, gallery, eyes, decoration, distance, painting, curtain, mirror, sign, show, eyesight, image; verbs: advertise, shine, splatter, peer, gaze, look, modify, look, look out, dress up, grimace, obscure, peep in, stare in wonderment, paint over, smudge, get dirty; adjectives/participles/adverbs: openwork, neat, artistically, asymmetric, faceless, cloudless, boundless, hopeless, shapeless, colorless, splendid, faded, catchy, prominent, visual.

- An audio predicate block. Nouns: accent, applause, bass, silence, conversation, howling, grunt, exclamation, harmony, dialect, voice, dialogue, discussion, dispute, dissonance, dialing; verbs: accompany, applaud, drum, bang, keep silent, talk, chat, mumble, mutter, gurgle, grumble, yell, screech, howl, roar, squeal, listen, coo, exclaim, call, shout out; adjectives/participles/adverbs: voiceless, unconditional, speechless, soundless, melodious, chatty, blatant, grouchy, aloud, harmonious, deaf, loud.

- A kinesthetic predicate block. Nouns: automatism, agony, adaptation, atmosphere, fragrance, impressions, depth, hunger, bitterness, density, pressure, smell, stench, itching, heartburn; verbs: weigh up, wave, freeze in, stink, sweat, swell, rub, squeeze, push, trample, grab, gnaw, burn out, exhaust, swallow, drag, dig deep; adjectives/participles/adverbs: fragrant, painful, tasteless, close, tasty, wet, half-starving, deep, hungry, hot, bitter, rough, pungent, burning, harsh, etc.

The answers were as follows: identification difficulties were classified as minimal (one on the scale from one to three); the time spent on determining one's own representative system ranged from 5 to 12 minutes; three visual, ten auditory, and three kinaesthetic learners were presented in the control group (identification error may be due to the dominance of auditory forms of control of students' knowledge at this stage of language learning on the bachelor's level).

At the stage of non-situational teaching of a foreign language according to the sensory-somatic code, the creation of a three-variant educational computer program for the study of associates and dissociates on the basis of fixing mental reactions by sensory ones is envisaged.

The simplest version of the program involves supporting the identification of associates and dissociates visually (for visual learners), audibly (for auditory learners), kinesthetically (for kinesthetic learners).

Simple forms of visual support can be coated (except for traditional - bold, underline, italics, color) on the background of emoticons, GIFs (Graphics Interchange Format), images in the PNG (Portable Bitmap Format), and APNG (Animated Portable Network Graphics) formats. Auditory support can be provided by the same resources as complex forms of visual support, but with the accompanying sound. Kinaesthetic support can be provided indirectly - through a visual representation of tactile action (approving or disapproving).

It seems efficient to consolidate the result using gradation - in the form of an increasing positive reaction. The easiest option is to fill the scale, as a result of which the student gains access to a certain achievement, manifested in the form of a collectible (1) / opening the next level (2) / bonus content (3). For consistent incorrect answers, such accumulation will be superfluous, since it will provoke a stressful state. Filling in the progress bar can be accompanied by a number of effects that are relevant for each form of sensory perception. So, it is visually easy to use the gradation of the brightness of the inscriptions or the background, as well as static images with signs of approval (JPEG), emoticons, stickers (PNG), animations (GIF). For the audio channel, this can be a sequence of phrases voiced (!) with an increase on the level of enthusiasm (good-great-excellent-perfect + yeah, nice, yep ...). The repetition of the same sound signifying success becomes irritating over time. A positive kinaesthetic reaction within the framework of the modern development of publicly available technologies can only be mediated, therefore, through visualisation, it is worth demonstrating only approving actions on an increasing basis (handshake, patting on the shoulder, hugs, etc.). 
Interruption of the line of correct answers is also easily accompanied by appropriate signals. Visually, this can be a reaction of another (traditionally red) color, a step back in increasing brightness, zeroing the scale, and also other described objects with a negative value. Auditory, it is a short unpleasant signal (as an option - a car horn), a voiced phrase of the class nope, try again, not really. It is important to avoid reactions like bad or terrible, leaving room for humour or student support. Kinaesthetic, in this case, is the use of vibration response of the devices, which is obvious.

The need for a reward system is an important detail in such games. Mastering a language (progress in learning it) itself cannot replace a full-fledged in-game reward.

Firstly, obtaining a set of collectibles that reflect various achievements appeals to the desire for completeness. Such a collection can include awards for mastering the topic, $\mathrm{N}$ correct answers in a row, $\mathrm{N}$ days of using the application without gaps, etc. It is also worth collecting statistics on all participants in order to demonstrate to the player that he answered the questions of the level, for example, $80 \%$ better than the rest.

Secondly, access to the next level only after completing the previous one is a practice that is relevant only when a thorough study of the topic is extremely important, when the skipping will really negatively affect the progress.

Finally, thirdly, bonus content is the most positive incentive option. Even the mythical cartoon at the end of the old electronic Just You Wait game made children spend hours repeating repetitive actions. Players strive to get something extraordinary, even if it costs them a lot of effort. In this case, access to interactive stories based on dissociation that will be both interesting and useful for students can be a great option.

All the methods of sensory influence described above were chosen taking into account the technical side, i.e. based on the current capabilities of wearable devices. The choice in favor of mobile devices over stationary ones (home PCs or specially equipped stations in the classroom) is due to their availability, popularity, and the possibility of constant use [21, 41-43]. Wearable devices can also be an excellent aid in learning pronunciation and speech recognition at the level of a native speaker. The use of technology to solve this problem was raised by Igarashi \& Wilson [44]. Modern mobile devices already know how to "talk" with a person, that is implemented in the function of the voice assistant Google Assistant, Siri, Alexa, etc. For mobile games, this feature can be used to build "live" dialogues with the option of adjusting the level of student speech recognition, taking into account the quality of pronunciation.

Modern devices are also ready for the use of augmented reality technologies for the purpose of teaching through games. So, access to certain topics, dialogues, activities can be tied to the geolocation of the device [45]. For example, while waiting for a flight at the airport, a student receives a notification from the application with a proposal to take several thematic levels. Other out-ofgame actions on the account can be taken into consideration, since information is already being collected, which is used to provide the learner with the most interesting content, as well as targeted advertising. The tutorial may also suggest topics of potential interest to the student.

All three types of reactions are aimed at stimulating the same blocks of associates and dissociates. As associates provide varying degrees of analogue transparency, the learning process must go from simple to complex, at the same time there should be constant support regarding the use of words that have been learned by framediscursive techniques.

The final phase of using analogue learning - a framesituational one (speech in simple situations as a result of filling the positions of typical communication frames) may be supplemented by more expensive for practical implementation, but forward-looking effective technologies of Mixed Reality, or Hybrid Reality [46]. The example of such a task can be the imitation of an act of minimum sufficient communication between virtually present participants outside the airport, hospital, store. Sensory-somatic enhancers in these situations will acquire a new quality, which is due to a combination of virtual resources of external projection of the situation and the real somatic reactions of the student. More distant is the perspective of using Extended Reality resources for teaching purposes, or, in other terms, Cross Reality, or Computer-Mediated Reality, which involve the interaction of student localised in the physical chronotope, the cognitive network, student avatar, other participants in the virtual situation. Thus, immersive technologies allow substituting finger interactions of a person with a machine, which is not characteristic of a human nature, by fruitful interactions of a new level. Studies of students' speech, which focus on the physical world, with tactile and olfactory feedback, have already been undertaken [47].

Our immediate task is to develop incentives for associative and dissociative teaching in the context of immersive virtual reality technology, here one teacher has the possibility to control the acquisition of knowledge by a large number of students or students have the possibility of total self-control. The difference between this methodology and well-known projects will be based on the individual sensory reactions of the student, in contrast to the already used Virtual Encyclopedia - Altair VR [48], where the student is a sensory uninvolved recipient. Ideally, it is even possible to create biological feedback sensors to test students' knowledge. If the proposed teaching methodology is supplemented by the possibility of organizing virtual student relaxation pauses based on associative and dissociative perception of reality, the project would be completed.

Sensory-somatic inductors appeared to be productive in learning a foreign language in the full spectrum of visual, auditory, tactile, gustatory, and odorative codes and were used by us in exercises of various types.

Exercises engaging reserves of sensory codes are ranked by levels. Exercises of the first and second levels of complexity have potential in learning parameterizable groups of vocabulary.

The first level exercises are based on abstract-symbolic categorization. 
A. Vocabulary rigidly associated with the perception of the world by means of sensory receptors.

The example of an exercise that employs visual code reserves. Find out what the following three phenomena have in common (grass, frog, crocodile - green color; snow, egg, polar bear - white color; sun, wheel, disk round; ice figure, ice cream, snow-covered mountain cold, etc.).

The example of an exercise that employs gustatory code reserves. Various objects are placed in three "baskets" according to the sensations they evoke (sweet, sour, bitter, etc.). The objects are taken out with the mouse cursor and named. At the stage of vocabulary presentation, objects can be "taken out" of the baskets, firmly linking the lexeme to the type of sensations, whereas at the training stage, they can be placed back.

B. Vocabulary related to the conveyance of emotions.

The example of an exercise that employs visual, auditory and tactile codes. A schematic representation of faces with the expression of various emotions (10 main ones, according to C. Izard) is proposed. The correct naming of emotions aloud when hovering the mouse cursor leads to the change of the presented emotion to the emotion of joy. The result is 10 images of smiling faces.

C. Thematic groups of vocabulary.

The example of an exercise that employs visual and tactile codes. You need to collect words denoting fruit/vegetables/children's toys in a "basket" by means of the mouse cursor (i.e., a verbal abstract-symbolic categorization is carried out). A properly stocked basket appears as a container with colorful images instead of words.

The example of an exercise that employs visual, auditory, and tactile codes. In a room with various objects, you need to collect the objects of a specific class by means of the mouse cursor and put them in a box (subject abstract-symbolic categorization), naming each object aloud. Correctly named objects turn into words that form a microfield.

Exercises of the second level of complexity are based on natural language categorization and cognitive effects.

A. Vocabulary rigidly associated with the perception of the world by sensory receptors.

The examples of exercises related to tactile (cold), visual (high), gustatory (tasty) sensations.

The exercise "Why representatives of different ethnic groups do not understand each other". The "Cold Winter" illustration portrays a Yakut in warm clothing and an African in the rain in light clothing; the "Tall Prickly Pear" illustration - a Masai and a Pygmy, whose heights are very different; the "Very Tasty" illustration - an image of fried insects in Thailand and jellied meat in Ukraine, and so on. The sound response suggests comparative characteristics of features ("In winter, the average temperature in northern Europe is much.... than in northern Africa, in Europe ...; a Masai is significantly ... than a pygmy, a Masai ...; common food seems to be ..., fried insects seem .... to a Thai person"). If the answer is correct, representatives of different ethnic groups offer their hands to each other.

B. Vocabulary related to the conveyance of emotions.

The exercise "Why representatives of different ethnic groups do not understand each other" is based on visual, auditory, tactile codes and designed similarly to the previous one based on illustrations. The illustration "Calm Conversation" depicts a typical conversation between an American and a Japanese person; "Joyful meeting" - a Finn and an Italian. Sound responses suggest comparative characteristics of features.

\section{Thematic groups of vocabulary.}

Collect from the components, naming them, a sample of an English house (thatched roof, chimneys, white walls, narrow windows, flowers, a cat in a window), a sample of a Swedish house (tiled roof, chimneys, wooden house, painted red/black/yellow colors, glass wall, flagpole and dog in the yard). The correct naming of the house components leads to the fact that the house appears in color, in case of incorrect naming the house falls apart.

Tasks of the third level of difficulty are based on an analogy with children's games that combine speaking and demonstration of actions, which is applicable in online learning. It is enough to record a series of videos with the actions of anthropomorphic visually attractive characters who would perform elementary actions, for example, movements (take - give), actions (stand - sit), while naming them aloud - using the audio channel (I dance, I draw). It is advisable to ask language learners also to perform the described actions - it is possible in the process of selfstudy. It is also possible to create an educational application in the genre of interactive cinema. The player becomes a participant in the process - the course of the plot depends on their decisions and phrases named or selected by the cursor (!). The plot turns can be elementary (Stimulus "Cold" - reaction "Put on a coat", "Rain" - "Take an umbrella") and more complex ("Shall we have dinner together? - Yes! - Where would you like to go - there is a choice"). The introduction of the student into such a "film" or comic strip is an effective element of involvement. An easy reading of the emotions, feelings of the characters as a result of the actions of the player works for understanding, the importance of decisions - for activating a sense of responsibility, an interesting story makes a person spend more time playing a game and learning.

The effectiveness of these exercises is due to the presence of sensory inductors that reinforce gnostic knowledge with perceptual sensations. 


\section{Conclusions}

The modern world, determined by the processes of globalisation, virtualisation, intensification of the information flow and, while remaining multilingually and ethnoculturally marked, requires changing educational trends in the field of learning a foreign language in favor of selfstudy and use of virtual and augmented reality technologies, but the main thing is to turn the learning process into a fascinating and effective one by introducing the learner into a flow state. The state of flow and the full involvement in the learning process with dominants of joyful anticipation, pleasure, full dedication and subconscious readiness for the rapid assimilation of new material is the result of the use of immersive (immersive) techniques and can be caused when mastering foreign languages due to computer learning or self-learning technologies. Our study has shown that it is promising to use the ontogenetically formed biological resource of a person, sensorysomatic enhancers, for modern teaching of foreign languages. Such enhancers take an important place among motivators for learning today, but according to the results of the students' survey, they can and should take a worthy place among enhancers for learning. In traditional methods of teaching foreign languages, sensory-somatic enhancers have found application only in the methods of suggestopedia in a broad sense. At the same time, their learning potential, as we have shown in our study, is clearly manifested in ethnic cross-generational children's games, systematically aimed at harmonizing the activity of the two hemispheres of the human brain, during which entertainment often gives way to effective learning. Sensorysomatic enhancers were used to develop the mnestic capacities of the people non-systemically, but gradually.

In the digital era, sensory-somatic enhancers were employed for foreign language learning in the NCNLP games. The use of sensory induction significantly affected the quality of the operator's work with the brain. The lively response of the student audience to the proposed sets of exercises based on sensory-somatic stimulation and the possibility of quick identification of the student's belonging to the group of dominant sensory perception, confirmed by a questionnaire, allowed us to create and offer for experimental testing educational complexes based on sensory induction. The proposed educational complexes of three levels of complexity, the samples of which have been introduced into the work, are based on the use of sensory enhancers in the study of parametrized (based on abstract and symbolic and natural-language systematization) vocabulary and on cognitive effects, as well as on the possibilities of reinforcing the student's mediated dialogue and computer programs (in the course of training through videos with a stochastic plot).

Modern teaching of foreign languages should be based on ontogenetically formed human biological resource sensory-somatic enhancers. Our research proves that sensory-somatic enhancers are historically proven effective means of teaching, systematically aimed at harmonizing the activities of the two hemispheres of the human brain. Sensory-somatic enhancers were used to develop mnestic capabilities of a person in a non-systematic but regular way.

Our proposed method of analogue teaching, combined with the methods of immersive technologies, promises to significantly accelerate and improve the learning process. The use of these methods is ergonomic at the preparatory stage (self-identification of students by representative systems), at the stage of non-situational language learning using augmented reality technologies (computer programs for visual, auditory, and kinesthetic learners). It is promising at the stage of frame-situational learning with involvement of mixed reality technologies. Other immersive technologies will inevitably be focused on sensorysomatic enhancers over time.

\section{References}

[1] D. Derryberry, D.M. Tucker, Developmental Psychopathology 2: Developmental Neuroscience, 502 (2015)

[2] M. Boekaerts, M. Zeidner, P.R. Pintrich, eds., Handbook of self-regulation, 1st edn. (Academic Press, New York, 1999)

[3] J.A. Bargh, T.L. Chartrand, American Psychologist 54, 462 (1991)

[4] R.G. Brockett, R. Hiemstra, Self-direction in adult learning, 1st edn. (Routledge, London, 1991)

[5] M.S. Knowles, Self-directed learning (Association Press, New York, 1975)

[6] N. Slukhai, L. Slavova, A. Flanagan, SHS Web of Conferences 75, 04008 (2020)

[7] B.B. Andresen, K. van den Brink, Multimedia in education (UNESCO Institute for Information Technologies in Education, Moscow, 2013)

[8] O. Burov, A. Kiv, S. Semerikov, A. Striuk, M. Striuk, L. Kolgatina, I. Oliinyk, CEUR Workshop Proceedings 2731, 1 (2020)

[9] P. Thornton, C. Houser, J. of Computer Assisted Learning 21, 217 (2005)

[10] T. Ishihara, J. Ham, Foreign language learning enhanced with cloud computing and mobile devices, in Proceedings of the 7th International Conference on E-learning, The Chinese University of Hong Kong (The Chinese University of Hong Kong, Hong Kong, 2012), pp. 158-161

[11] M.I. Striuk, S.O. Semerikov, A.M. Striuk, Information Technologies and Learning Tools 49, 37 (2015)

[12] D. Khampusaen, Int. J. of the Computer, the Internet and Management 22, 87 (2014)

[13] O.M. Markova, S.O. Semerikov, A.M. Striuk, Information Technologies and Learning Tools 46, 29 (2015)

[14] M. Ebrahimzadeh, S. Alavi, Electronic J. of Foreign Language Teaching 14, 145 (2017)

[15] A. Tokarieva, N. Volkova, I. Harkusha, V. Soloviev, CEUR Workshop Proceedings 2433, 74 (2019)

[16] M. Kruk, ed., Assessing the effectiveness of virtual technologies in foreign and second language instruction (IGI Global, 2018) 
[17] S. Symonenko, N. Zaitseva, V. Osadchyi, K. Osadcha, E. Shmeltser, CEUR Workshop Proceedings 2547, 37 (2020)

[18] E. Yudkowsky, in Global Catastrophic Risks (Oxford University Press, Oxford, 2008), pp. 308-345

[19] O. Chorna, V. Hamaniuk, A. Uchitel, CEUR Workshop Proceedings 2433, 294 (2019)

[20] V. Ustinova, S. Shokaliuk, I. Mintii, A. Pikilnyak, CEUR Workshop Proceedings 2433, 308 (2019)

[21] Y. Kazhan, V. Hamaniuk, S. Amelina, R. Tarasenko, S. Tolmachev, CEUR Workshop Proceedings 2643, 392 (2020)

[22] R. Tarasenko, S. Amelina, Y. Kazhan, O. Bondarenko, CEUR Workshop Proceedings 2731, 129 (2020)

[23] S.S. Palchevskyi, Suggestopedagogy: the latest educational technologies (Condor, Kyiv, 2005)

[24] R. Waterfield, Hidden depths: The story of hypnosis, 1st edn. (Macmillan, London, 2002)

[25] W. James, The Principles of Psychology (Henry Holt and Company, 1890)

[26] G. Bateson, M.C. Bateson, Angels fear: towards an epistemology of the sacred (Bantam Books, Toronto, 1988)

[27] G. Bateson, Steps to an ecology of mind, 2nd edn. (Jason Aronson Inc., London, 1987)

[28] N.V. Slukhai, Suggestive linguistics: Linguistic programming of human behavior (Dmytro Burago Publishing House, Kyiv, 2019)

[29] M. Csikszentmihalyi, Flow: The psychology of optimal experience, 1st edn. (Harper and Row, New York, 1990)

[30] S. Wang, A. Voiskunsky, O. Mitina, A. Karpukhina, J. of the High School of Economics 8, 73 (2011)

[31] Ministry of Defence of Ukraine, How the international center for peacekeeping and security trains the memory of servicemen for combat conditions (2020), https://tinyurl.com/2257nxa2

[32] G. Bateson, Mind and nature: a necessary unity, 1st edn. (Dutton, New York, 1979)

[33] V.S. Pantelidis, Themes in Science and Technology Education 2, 59 (2009)

[34] Y.V. Kornylov, Azimuth of Scientific Research: Pedagogy and Psychology 8, 174 (2019)
[35] A.V. Zamkov, Mediaskop (2017)

[36] Z. Lv, A. Halawani, S. Feng, S. Feng, H. Li, S.U. Réhman, ACM Transactions on Multimedia Computing, Communications and Applications 11, 1 (2014)

[37] V.V. Dobrova, P.H. Labzyna, Bulletin of Samara State Technical University. Psychological and Pedagogical Sciences 4, 16 (2016)

[38] L.R. Nurtdinova, Bulletin of Samara State Technical University. Psychological and Pedagogical Sciences, 2017 1, 57 (2017)

[39] N.V. Ageenko, D.D. Dorofeeva, Bulletin of Samara State Technical University. Psychological and Pedagogical Sciences 2, 6 (2017)

[40] S.I. Ozhegov, N.Y. Shvedova, Explanatory dictionary of the russian language, 4th edn. (Azbukovnik, 1997)

[41] Y. Modlo, S. Semerikov, P. Nechypurenko, S. Bondarevskyi, O. Bondarevska, S. Tolmachev, CEUR Workshop Proceedings 2433, 413 (2019)

[42] O. Pavlenko, O. Bondar, B. Yon, C. Kwangoon, N. Tymchenko-Mikhailidi, D. Kassim, CEUR Workshop Proceedings 2433, 279 (2019)

[43] V. Tkachuk, Y. Yechkalo, S. Semerikov, M. Kislova, V. Khotskina, CEUR Workshop Proceedings 2732, 1217 (2020)

[44] K. Igarashi, I. Wilson, SHS Web of Conferences 77, $02003(2020)$

[45] D.S. Shepiliev, S.O. Semerikov, Y.V. Yechkalo, V.V. Tkachuk, O.M. Markova, Y.O. Modlo, I.S. Mintii, M.M. Mintii, T.V. Selivanova, N.K. Maksyshko et al., Journal of Physics: Conference Series 1840, 012028 (2021)

[46] A. Iatsyshyn, V. Kovach, V. Lyubchak, Y. Zuban, A. Piven, O. Sokolyuk, A. Iatsyshyn, O. Popov, V. Artemchuk, M. Shyshkina, CEUR Workshop Proceedings 2643, 134 (2020)

[47] E. Richard, A. Tijou, P. Richard, J.L. Ferrier, Virtual Reality 10, 207 (2006)

[48] O. Honcharova, M. Momot, Complete immersion: how immersive learning comes to companies and schools (2019), https: //trends.rbc.ru/trends/education/ 5d6fb3449a794781b981b437 